Chapter 5

\title{
Stress Corrosion Cracking of Ductile Ni-Resist Irons and Stainless Steels
}

\author{
Osama Abuzeid, Mohamed Abou Zour, \\ Ahmed Aljoboury and Yahya Alzafin \\ Additional information is available at the end of the chapter \\ http://dx.doi.org/10.5772/52318
}

\section{Introduction}

Potable water, in the Arabian Gulf and many other regions around the world, is mainly produced by desalinating seawater. Multi-stage flashing chambers (MSF) desalination plants are reported to account for producing about $85 \%$ of the desalinated water in the world [1]. In these plants, large heavy duty vertical brine circulation pumps (BCP) are used. Brine is a very corrosive environment rich in chlorides. During their operation, $\mathrm{BCP}$ are subjected to continuous hydraulic and mechanical loading while handling a very corrosive environment with high chloride content. These operating conditions are enough to initiate stress corrosion cracking SCC. Failure of these critical pumps would result in costly shut downs of the desalination plant and thus affecting plant reliability and availability. The rotating parts of brine circulation pumps are usually made out of austenitic stainless steels or duplex stainless steels, whereas, pressure casings had been made out of ductile Ni-resist irons (DNI) at least till the 1990's, beyond which more resistant materials have been the preferred choice of construction; e.g. Duplex Stainless Steels. It is however a fact that many of the pumps in operation are still made of DNI which are highly alloyed class of cast irons. The main alloying element in DNI is Nickel and its content varies between $18 \%$ and $22 \%$, giving its austenitic microstructure and its desirable corrosion resistance properties. Their microstructure is characterized by uniformly distributed nodular graphite in an austenitic matrix which also contains carbide areas. DNI have also good erosive wear resistance, good machineability, castability and controlled expansion.

Meanwhile, austenitic and duplex SS materials are gaining more popularity as pump casings materials than DNI in brine environment. In addition to cast stainless steels, original pump manufacturers sometimes use welded construction of wrought stainless steels to 
build other related components such as column pipes and discharge elbow piece [2]. Due to the difference in expensive alloying, and apparently higher demand in many appliactions, austenitic SS is cheaper than duplex and superduplex SS. However, the mechanical, corrosion and SCC properties of duplex and superduplex SS are superior to that of austenitic SS. Therefore, economically, the idea of using chemical corrosion inhibitors to enhance the SCC resistance of the austenitic SS, is appealing, non famous and worth looking at.

In this chapter, design and construction of an SCC testing rig and testing method are described. A comparison between two types of widely used DNI in building BCP is carried out. Mechanical, metallurgical, electrochemical and SCC test results are reported. This is followed by presenting similar test results for two types of stainless steel that started replacing DNI in manufacturing pump casings [3]. Wrought stainless steel samples of the two types are used in performing the comparison between the behavior of the two types. Finally an attempt is reported to improve the immunity of the cheaper austenitic stainless steel through using chemical treatment via one proven performance corrosion inhibitor.

\section{SCC testing rig and method}

Fig. 1 shows a photograph for a constructed SCC test rig [2]. The rig is designed to simulate real service conditions in a desalination plant. It comprises a proof ring containing a testing chamber, a constant load tightening screw system, brine container with heating plate and other attached accessories such as electrodes, wiring to an ACM potentiostat, a computer, a dial indicator to monitor ring deflection during SCC testing and a web monitoring camera. The proof ring is made from a duplex stainless steel and is used to control the load on the SCC test samples. It is welded to upper and lower bosses. Both bosses were drilled through the ring. The lower boss is used to fix the ring in place, whereas, the upper boss is used in mounting the tightening screw loading system. A $100 \mathrm{kN}$ (MTS) tension compression testing machine can be used to calibrate the bossed ring to convert its axial deflection into axial load on the SCC sample. The SCC testing chamber which is made from transparent acrylic tube is used to accommodate the SCC testing sample, hot brine, electrodes and a thermocouple. A top and bottom Teflon covers, each with an $\mathrm{O}$ ring seal, are used together with the acrylic tube to form the testing chamber. Four holes are drilled in the top cover to fit the working electrode (SCC sample), auxiliary electrode, reference electrode, and a thermocouple. A constant tensile load mechanism consisting of a tightening screw and nut system made from 316L stainless steel is used to pull up the tested sample. A tightening nut is used to maintain the ring deflection to a level corresponding to the required tensile load as given by the calibration data of the proof ring.

To ensure that only tensile stresses are transmitted to the sample without any torsion shear stresses, a properly devised stressing jig can be used. Inside the testing chamber, samples are subjected also to circulated hot brine of controlled temperature between $55^{\circ} \mathrm{C}$ and $60{ }^{\circ} \mathrm{C}$. 


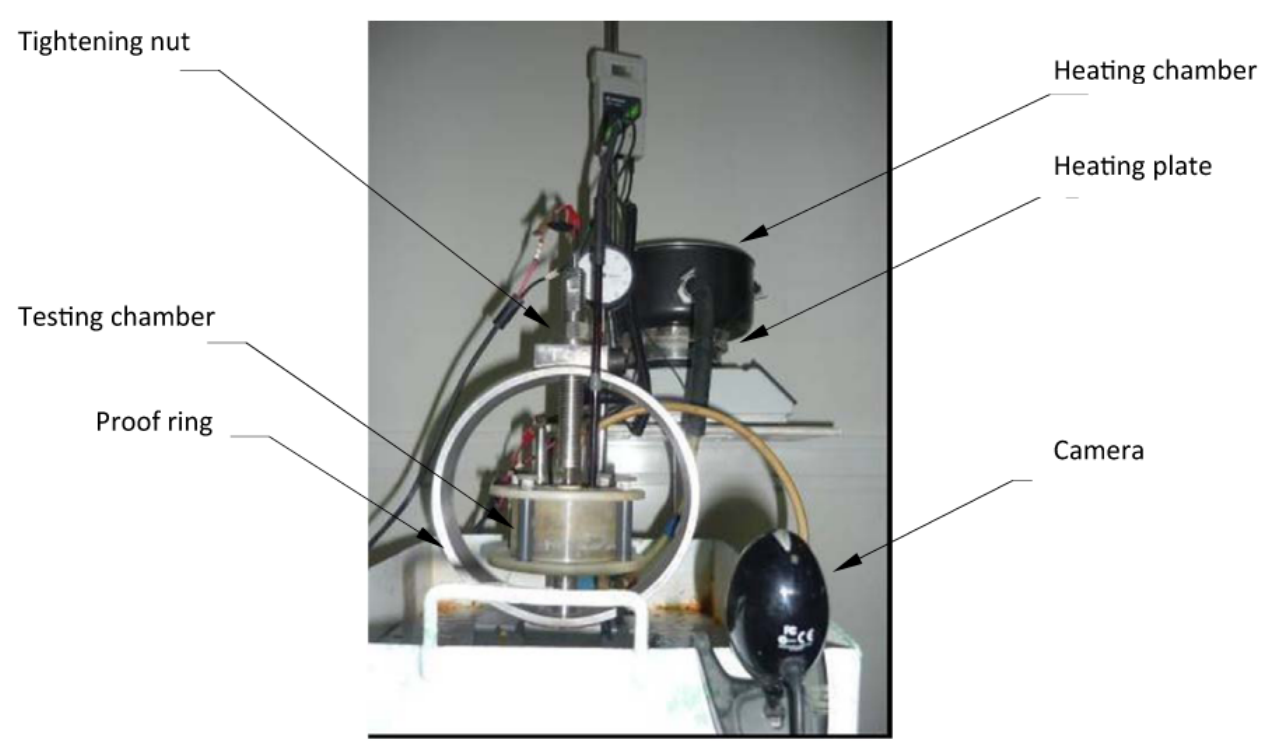

Figure 1. SCC test rig designed following the guidelines of ASTM and NACE Type A testing method [4, 5]. a) proof ring, b) SCC testing chamber, c) tightening screw and nut system, d) hot brine container, e) heating plate, f) monitoring camera [2].

A Teflon coated aluminum container, with an over flow floating valve, is used to heat the brine received from a higher level supply tank. A hot plate with a controlled power switch is used to heat the brine in the container to the required testing temperature. The heated brine is then delivered by gravity to the SCC testing chamber and hence to a disposal tank. A web monitoring camera is mounted and adjusted to record one shot each 30 min in order to detect movements of the dial indicator and hence failure of samples. Auxiliary and reference electrodes are immersed inside the testing chamber through the top Teflon cover. An ACM potentiostat (model Gill 6) is used to apply the required accelerated anodic potential during SCC testing. ACM Sequencer software is used to record the test results. An offset anodic potential with respect to the rest potential of each tested sample is normally used. The value of this accelerating anodic potential is determined from cyclic sweep and depends on the required degree of acceleration and any observed pitting potential values. During SCC testing the sample is subjected to a constant load representing a high ratio of the yield load of the tested sample. Each SCC test is stopped upon sample fracture or completion of predetermined value of testing hours, whichever comes first. Samples which are not completely separated into two pieces, by SCC tests, are subsequently forced to mechanical tensile fracture using the MTS testing machine. Fracture sections of the mechanically forced fractured samples can be examined using the scanning electron microscopy SEM. These sections can be also compared with fracture sections of fresh samples not subjected to SCC testing. The ultimate tensile loads of both fresh and mechanically forced fractured samples can be also compared. 


\section{Ductile Ni resist- cast irons DNI}

DNI are highly alloyed class of cast irons. Their main alloying element is Nickel and its content varies between $18-22 \%$ as per relevant standards giving its austenitic microstructure and its desirable corrosion resistance properties. Other alloying elements such as chromium are present even though in lower percentages than nickel. Ni-resists come in a variety of compositions depending on their intended applications. For sea water applications which include brine circulation pumps, chemical compositions of two common grades of ductile Ni-resist in relation to the permissible range of composition as per the ASTM A439 D2 are indicated in table 1 [6].

\begin{tabular}{lccccccccc}
\hline Grade & $\mathbf{C}$ & $\mathbf{S i}$ & $\mathbf{M n}$ & $\mathbf{P}$ & $\mathbf{N i}$ & $\mathbf{C r}$ & $\mathbf{M g}$ & $\mathbf{N b}$ & $\mathbf{C u}$ \\
\hline ASTM [A439 D2] & Max 3.0 & $1.5-3.0$ & $0.7-1.25$ & Max 0.08 & $18-22$ & $1.75-2.75$ & - & - & - \\
\hline D- Material: ASTM & 2.69 & 2.58 & 0.83 & 0.013 & 18.9 & 2.12 & 0 & 0 & 0 \\
\hline G- Material: [BS3468 S2W] & 2.77 & 1.94 & 1.03 & 0.015 & 20.1 & 1.66 & 0.043 & 0.15 & 0.08 \\
\hline
\end{tabular}

Table 1. Reported chemical compositions of the D and G-types ductile Ni-resist irons in relation to the permissible range of composition as per the ASTM A439 D2 [6]

The authors of this chapter have investigated the corrosion failure of the pressure parts of brine circulation pumps, made of DNI, in a desalination plant located on the Arabian Gulf $[6,7]$. Two brands of pumps had been reported to have different lives to total failure; one lived 18 years while the other lasted only five years. The failed parts of former pumps were made out of DNI material as per ASTM A439 D2 (denoted in table 1 by D-material), whereas, those of latter pumps were made out of DNI material as per BS 3468 S2W (denoted by Gmaterial), which has better weldability.

The material factor, as one of other possible factors that could have contributed to this different behavior, has been evaluated. Metallurgical examinations using scanning electron microscopy (SEM), image analysis, tensile tests and Vickers hardness tests were used to study the microstructure, and mechanical properties of both alloys. Electrochemical and SCC tests were performed in brine solutions to evaluate the corrosion and SCC behaviors of both alloys. The following represents a summary for the experimental work, results and conclusions of this investigation.

\subsection{Experimental work}

\subsubsection{Image analysis and mechanical testing}

Samples for all types of tests were cut from failed parts of the brine circulation pumps. Samples for metallurgical examinations were, ground, using a rotary grinder with emery paper grades up to 2400 . Ground specimens were polished using a rotary polishing machine with 
diamond paste up to $0.25 \mu \mathrm{m}$. Samples were then etched using $2 \%$ Nital solution $(2 \%$ Nitric acid in $98 \%$ Ethanol).

Classification of graphite nodules, in both types of cast irons, in terms of average nodule diameter, number of nodules per square millimeter and average aspect ratio of nodules were determined using SEM images and Ks 300 Kontron Elektronik image analysis software. Hardness and tension tests were conducted using standard Vicker harness tester and $100 \mathrm{kN}$ MTS tensile testing machine respectively. Tensile test specimens, having a gauge diameter of $12.5 \mathrm{~mm}$ were prepared from both types of cast iron and tension tests were conducted as per ASTM standard [8].

\subsubsection{Preparation and examination of specimens with cracks induced during plant service}

To permit SEM examination of the fracture surface initiated by SCC during service one specimen each from both D and G materials of approximately 2 in. $x 1$ in. $x 1$ in. and having cracks with crack front were cut out from failed pump casings. Threaded holes were prepared and special fixtures were fabricated to open the crack surfaces using an MTS machine without damaging the crack surfaces. Fig. 2a illustrates a specimen ready for crack opening. Hexa methylene tetra amine solution was used according to ASTM G1 [9] to remove as much as possible of corrosion products from fracture surface. Two other specimens, as shown in Fig. 2b, with SCC cracks were also sampled from failed pump casings and prepared for optical microscopy to examine nature of crack propagation in the matrix and other present phases.

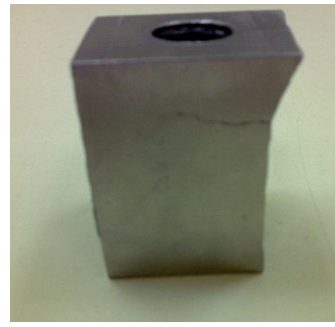

(a)

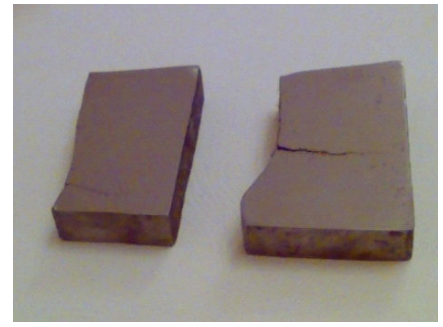

(b)

Figure 2. Two photographs of (a) G specimen prior to crack opening with the SCC appearing at top of front face and (b) G and D specimens, sampled from failed pump casings with cracks for optical microscopy [7].

\subsubsection{Electrochemical testing}

Hollow cylindrical test specimens having $12.4 \mathrm{~mm}$ outside diameter and $7.94 \mathrm{~mm}$ height of each type of cast iron, were machined from pieces cut from real failed pumps. Following machining, specimens were stress relieved as per the ASTM guidelines [10], chemically cleaned as per the ASTM [9] and mechanically ground using emery papers up to 600 grade. Specimens were then degreased with acetone and cleaned with fresh water prior to electrochemical testing. The corrosive environment used was brine solution (concentrated sea water of Arabian Gulf) having an average chloride concentration of 34,000 ppm. This was 
arranged from the desalination plant where pump failures have occurred. ACM potentiostat and software system were used for testing. The test apparatus and shape of test specimens used in electrochemical and SCC tests are shown in Fig. 3 [6]. Prepared specimens were subjected to both long term linear polarization resistance (for corrosion rate determination) and rest potential measurements. These measurements were carried out over a period of about two days at room temperature $\left(25 \pm 2{ }^{\circ} \mathrm{C}\right)$. The above tests were directly followed by potentiodynamic sweeps to compare between the corrosion behaviors of both alloys.

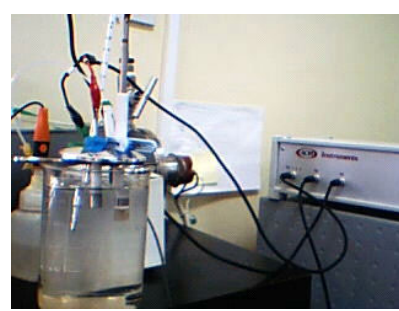

(a)

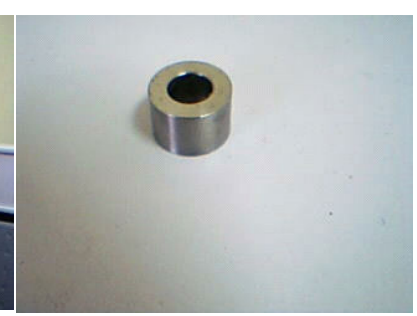

(b)

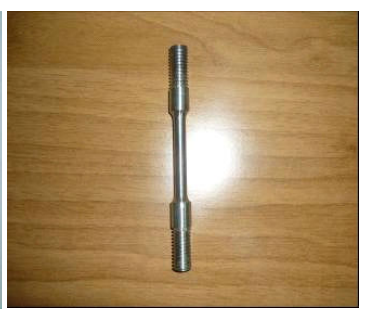

(c)

Figure 3. Setup of electrochemical testing (a), an electrochemical test sample (b), and an SCC test sample (c) $[2,6]$.

\subsubsection{SCC tests}

The materials of both D and G materials were cut out from pump casings that failed by SCC. Locations of cuts were selected to be as near to crack area as possible. This is to ensure, to the extent possible, that microstructures of test materials are not different from that of the cracked areas. According to ASTM [11] standard A370 tensile round SCC test specimens having a small size gauge diameter of $6.25 \mathrm{~mm}$ were machined from the cut D and $\mathrm{G}$ testing materials, see Fig. 3.c. Machined specimens were subjected to stress relief heat treatment, according to ASTM A439 [9], and mechanically cleaned with emery papers to remove oxide scales resulting from the stress relief process. The specimens had then their gauge surfaces ground to 600 grit size. A Resin coating was applied at fillets and shoulders of the specimens to seal the test cell at specimen insertion holes from brine leakage. The specimen portion exposed to brine during stress corrosion testing is $20 \mathrm{~mm}$ of the gauge length. The threaded portions were taped to keep them clean. After the SCC testing the fracture surfaces of failed SCC test specimens were chemically cleaned using hexa methylene tetra amine solution [10] to remove as much as possible of corrosion products.

In order to accelerate the SCC testing, the specimens were subjected to following test conditions. First, air was allowed to contact the brine stored in an overhead tank. Second, continuous supplies of brine ensure that the brine in the test cell stays fresh and rich in chlorides hence maintaining its corrosiveness. Third, the brine solution temperature was raised to around $55{ }^{\circ} \mathrm{C}$. From Miyasaka's work it was found that this temperature is high enough to significantly accelerate SCC of DNI [12]. Fourth, specimens were all anodically polarized by $100 \mathrm{mV}$ with respect to their free corrosion potential. Finally, all specimens were highly 
stressed between $73 \%$ and $102 \%$ of their respective $0.2 \%$ offset yield strengths. A total of eight specimens; four from each alloy were SCC tested. Table 2 shows the details of the stress levels of the tested samples. The applied stresses were chosen as follows. Two specimens from each of the G and D materials were tested at around $220 \mathrm{MPa}$. This is approximately $100 \%$ and $86 \%$ of the yield stresses of the $\mathrm{G}$ and $\mathrm{D}$ material respectively. For unbiased comparison, two G specimens were also tested at around $86 \%$ of their yield stress. Two other D specimens were tested at stress levels around the $86 \%$ and $93 \%$ of the yield stress of the G material (73.3\% and $79.2 \%$ of the yield stress of the D material) for comparison. Stressing the specimens was carried out, using the proof ring described earlier in this chapter, after inserting the specimen in the test cell.

\begin{tabular}{lcccccccc}
\hline Sample & G1 & G2 & G3 & G4 & D1 & D2 & D3 & D4 \\
\hline Stress, MPa & 225 & 216.5 & 190.4 & 190.4 & 224.5 & 216.5 & 190.6 & 205.9 \\
\hline \%, of yield* & 102 & 98.4 & 86.5 & 86.5 & 86.4 & 83.4 & 73.3 & 79.2 \\
\hline
\end{tabular}

*Percentage of $0.2 \%$ offset yield stress of each alloy.

Table 2. Details of the stress levels of the tested samples [7].

Once the specimen was stressed various connections were made. The heater was set at $55{ }^{\circ} \mathrm{C}$ using a heater element thermostat and a PC-connected camera was then hooked around the test cell using rubber bands. The camera software was set so as to take photos at intervals of 15 min. The specimen was then polarized using ACM potentiostat and software. After admitting the brine solution and reaching the test temperature at $\left(55 \pm 3^{\circ} \mathrm{C}\right)$, the camera was activated, the potentiostat was run and the time to full fracture was recorded visually with the camera.

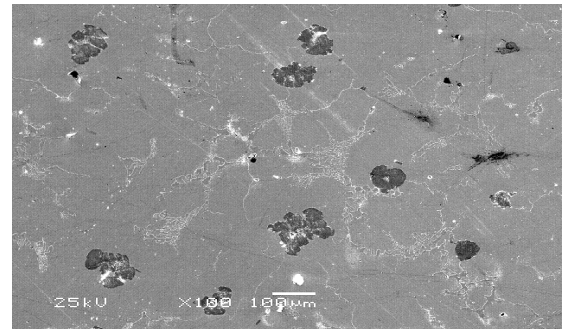

(a)

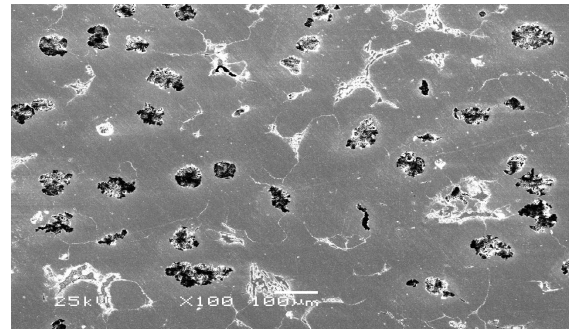

(b)

Figure 4. SEM micrographs showing the difference between the microstructures of the D-type (a) and the G-type (b) of the Ni-Resist austenitic cast irons [6].

\subsection{Results and discussion}

Fig. 4 shows SEM micrographs, illustrating the difference between the microstructures of the D-type (a) and the G-type (b) of the Ni-resist ductile irons [6]. Table 3 shows the image analy- 
sis results for both types of cast iron. These results show that the number of graphite nodules per square millimeter for the D-type cast iron is almost half the number of that for the G-type. However, the average nodule diameter of the D-type is greater than that for the G-type.

Table 3 also shows that the graphite nodules of the D-type are more circular in cross section than the nodules of the G-type cast iron. This is illustrated by the higher average aspect ratio of the D-type nodules as compared to the average aspect ratio of the G-type nodules.

\begin{tabular}{lcc}
\hline & D-type & G-type \\
\hline Field area $(\mathrm{mm} 2)$ & 4.505 & 4.505 \\
\hline Number of nodules & 113 & 227 \\
\hline Number of nodules / mm2 & 25.08 & 50.39 \\
\hline Average nodule diameter $(\mu \mathrm{m})$ & 43.67 & 31.54 \\
\hline Average aspect ratio & 0.717 & 0.645 \\
\hline Percentage area of graphite to the total field area & $3.8 \%$ & $2.09 \%$ \\
\hline
\end{tabular}

Table 3. Image analysis of the D and G-Types of the Ni-Resist austenitic cast irons [6].

The SEM micrographs of Fig. 4 also show that carbides are more uniformly distributed within the microstructure of the D-type cast iron. This can explain the relatively higher Vickers hardness number and tensile strength of this type of cast iron. Average Vickers hardness values, HV5, of 220 and 200 have been measured for the D and G-types, respectively. Fig. 5 shows that the $\mathrm{D}$ type has a higher $0.2 \%$ offset yield strength of $260 \mathrm{MPa}$ as compared to the $220 \mathrm{MPa}$ of the G-type. The modulus of elasticity of both materials is about $131 \mathrm{GPa}$ which is on the upper side of the range reported in the standards [13]. The EDX chemical analysis within the field area of these micrographs shows that $\mathrm{Cr}$ is basically existing in carbides rather than being free in the matrix.

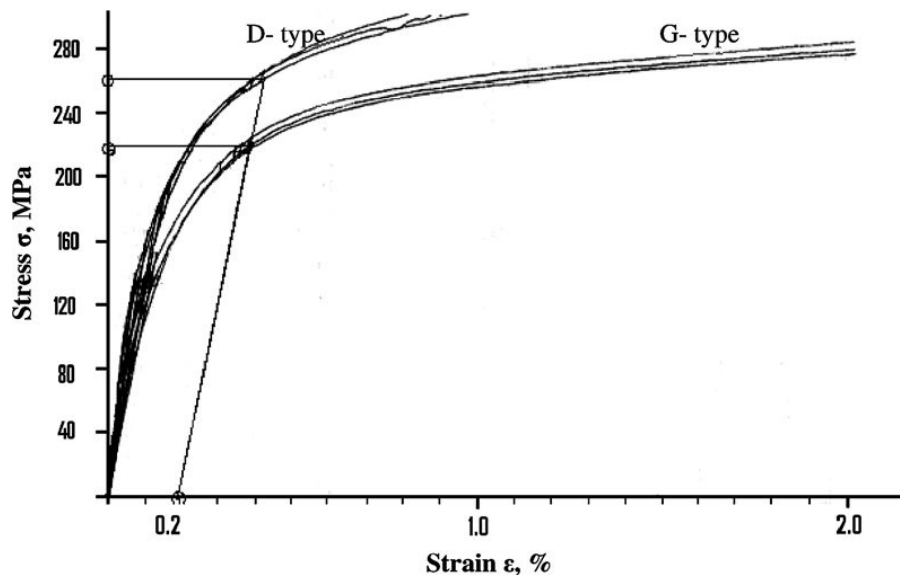

Figure 5. Stress-strain plots for the two types of nickel-resist cast irons [6]. 
Results of corrosion rates and rest potential measurements are shown in Fig. 6. The corrosion rates stabilized between at $0.2-0.25 \mathrm{mmpy}$ and the potentials ranged between $-450 \mathrm{mV}$ and $-500 \mathrm{mV}$, all with respect to $\mathrm{Ag} / \mathrm{AgCl}$ reference electrode. Similar results have been reported in literature [14]. Fig. 7 shows the Tafel plots for the two cast iron materials. Both types showed similar behavior in shape of curves even though the rest potentials varied from $-500 \mathrm{mV}$ to -650 $\mathrm{mV}$ without any distinctive pattern for either type of materials. Severe corrosion process took place at potentials greater than $100 \mathrm{mV}(\mathrm{Ag} / \mathrm{AgCl} \mathrm{RE})$ anodic to the rest potential. This was accompanied by blackish thin corrosion layer and rigorous bubbling at the surface of the cylindrical counter electrode (made of duplex stainless steel). Similar results in synthetic sea water environment $(3 \% \mathrm{NaCl})$ solution at $25^{\circ} \mathrm{C}$, have been reported [15].

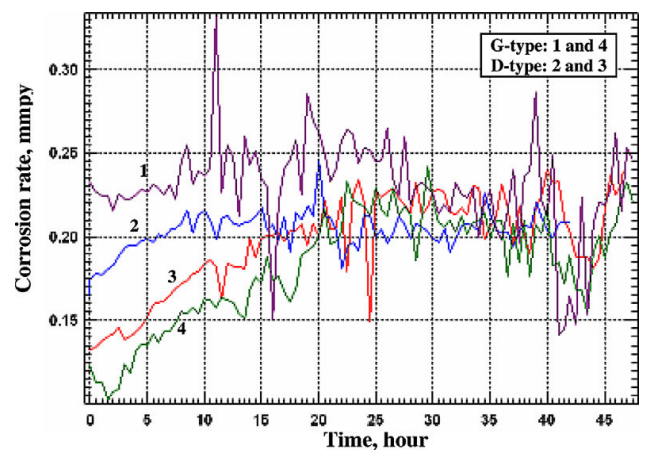

(a)

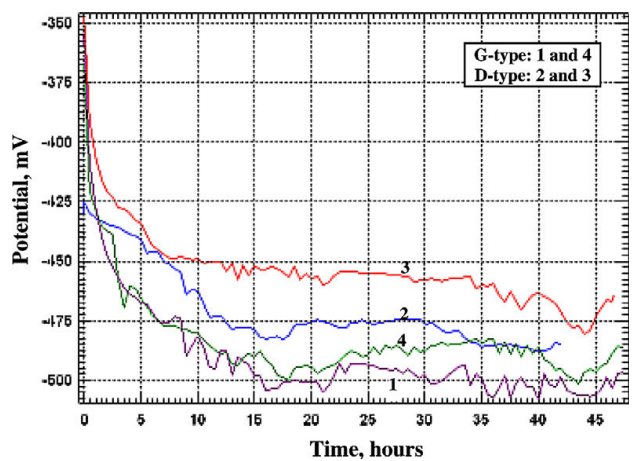

(b)

Figure 6. Corrosion rates (a) and potentials (b) of four specimens (two from each D and G materials). Potentials are measured versus $\mathrm{Ag} / \mathrm{AgCl}$ reference electrode [6]

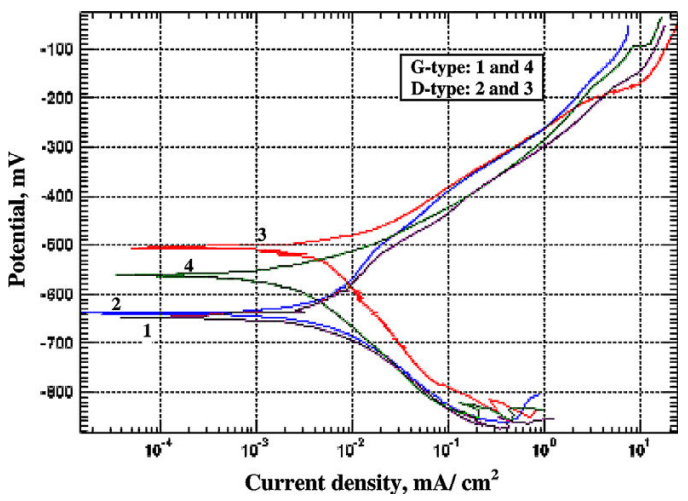

Figure 7. Tafel plots of four specimens (two from each D and G-type materials). All potentials are measured versus $\mathrm{Ag} / \mathrm{AgCl}$ reference electrode [6]. 
Thus, electrochemical corrosion tests, in brine solution at room temperature, have shown similar corrosion behavior, in terms of corrosion rates, potential and polarization. To compare between the combined effects of strength and corrosion resistance of both alloys, SCC tests were performed.

The two specimens, sampled from failed pump casings, for examination of the crack surfaces were opened till fracture using special holders prepared for this purpose. Figure 8 shows two photographs for the fracture surfaces of the two materials. They show corroded and mechanically fractured areas. Figure 9 shows photographs for the service induced SCC of the two materials. All cracks pass through the matrix without preference to phases. Figure 10 shows SEM micrographs of fracture surfaces of the same specimens shown in figure 8 . They indicate two distinctive fracture surfaces. The first is the mechanical fracture surface caused by loading using the MTS tensile testing machine and the second is the SCC fracture surfaces developed during pump service. The second surfaces are similar to those reported in literature [16].

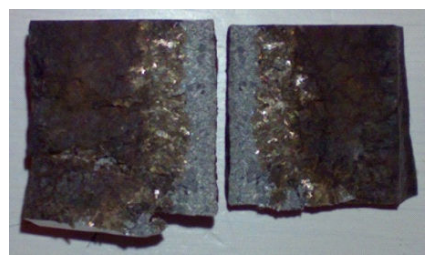

(a)

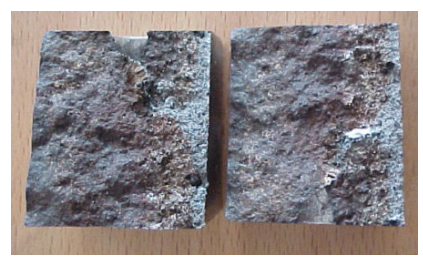

(b)

Figure 8. Two photographs showing (a) G material as fractured prior to cleaning and (b) D material after chemical cleaning [7].

The life times to full fracture of various tested specimens are indicated in Table 4 . As can be seen from the table, all G specimens fractured during the tests. Out of the 4D specimens only specimen D1 fractured. These results tend to agree with times to failures reported in actual plant service with D material outperforming $G$ material ( $G$ failed in 5 years whereas $D$ failed in around 18 years). Fig. 11 shows SEM micrographs of fracture surfaces of SCC tested D and $\mathrm{G}$ materials. These micrographs of fractured surfaces clearly indicate a fracture pattern of two different surface morphologies. While much of the fracture surface has dimpled nonflat areas characteristic of purely mechanical fracture, there are flat areas extending from edges of the specimen. They also contain sudden vertical steps and transverse cracks do exist in the flat areas in many instances. They also are characteristic of transgranular SCC agreeing with those available in literature as reported by Kauczor [16]. This fracture pattern matches with the fracture pattern obtained and presented in Fig. 9 for the samples collected from the casings of the service failed pumps. This emphasizes that the cause of failure of the casings of the failed pump is stress corrosion cracking. 


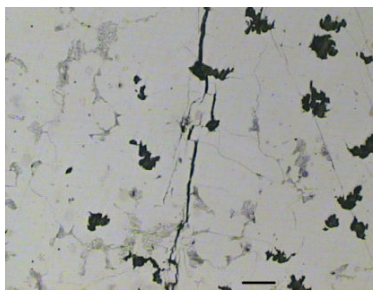

(a)

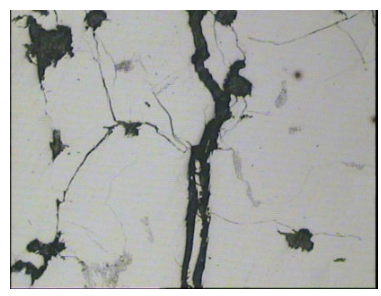

(c)

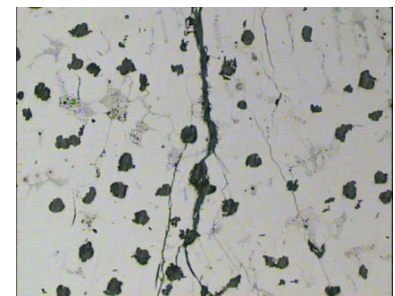

(b)

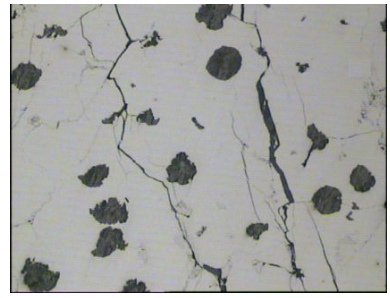

(d)

Figure 9. Service induced SCC cracks of D material at (a) 100X and (c) 200X and those of G material (b) 100X and (d) 200X. Cracks propagate through matrix without preference to phases [7].

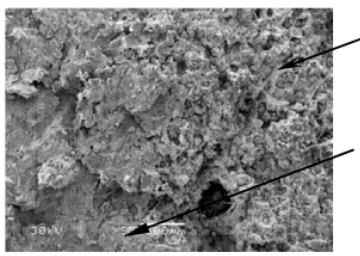

(a) $X=35$

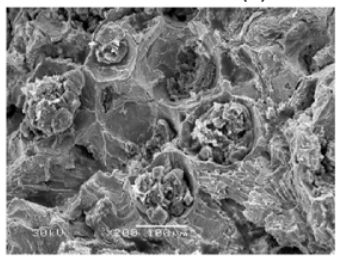

(b) $X=200$

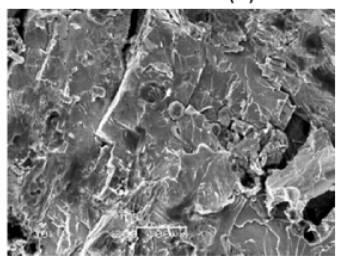

(c) $X=200$
Dimpled mechanical fracture surfaces

Flat SCC fracture surfaces developed during pump service

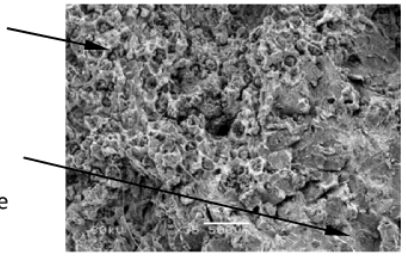

(d) $X=35$

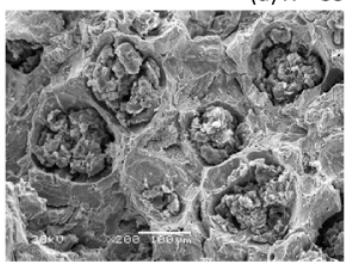

(e) $X=200$ Dimpled mechanical fracture surfaces at higher magnification. $X=200$

Flat SCC fracture surfaces developed during pump service at higher magnification. $X=200$

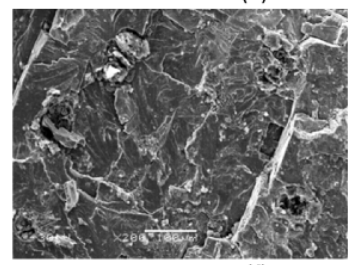

(f) $X=200$

Figure 10. SEM micrographs of fracture sections of D material $(a, b$, and $c)$ and $G$ materials ( $d$, e, and f). SCC fracture surfaces were produced during pump service, whereas, mechanical fracture surfaces were produced due to specimen forced fracture using MTS testing machine [7]. 


\begin{tabular}{lcccccccc}
\hline Sample & $\mathbf{G}_{\mathbf{1}}$ & $\mathbf{G}_{\mathbf{2}}$ & $\mathbf{G}_{\mathbf{3}}$ & $\mathbf{G}_{\mathbf{4}}$ & $\mathbf{D}_{\mathbf{1}}$ & $\mathbf{D}_{\mathbf{2}}$ & $\mathbf{D}_{\mathbf{3}}$ & $\mathbf{D}_{\mathbf{4}}$ \\
\hline Applied stress, MPa & 225 & 216.5 & 190.4 & 190.4 & 224.5 & 216.5 & 190.6 & 205.9 \\
\hline \%, of 0.2\% offset yield & 102.3 & 98.4 & 86.7 & 86.5 & 86.4 & 83.4 & 73.3 & 79.2 \\
\hline Time to failure, hours & 37.6 & 86.5 & 100.5 & 72.5 & 167.5 & $184.8-$ TS $^{* *}$ & $254-$ TS & $209-$ TS \\
\hline Remarks $^{* *}$ & FF & FF & FF & FF & FF & NF & NF & NF \\
\hline
\end{tabular}

* $0.2 \%$ offset yield of G $=220 \mathrm{MPa}$. 0.2 offset yield of $\mathrm{D}=260 \mathrm{MPa}[6]{ }^{* *} \mathrm{TS}=$ Test stopped without fracture ${ }^{* * *} \mathrm{FF}=$ Full fracture, and NF = No fracture.

Table 4. Time to SCC failure of tested specimens of. G and D materials [7].

The above results suggest that as other factors are neutralized the material factor has a significant role in the reported contrasting performance of DNI with respect to resistance to SCC.

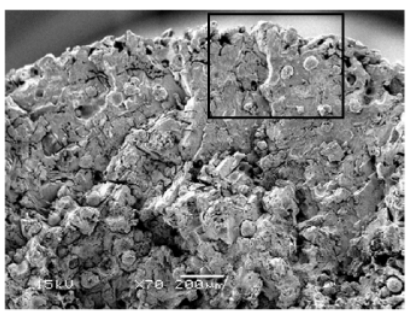

(a) $X=70$

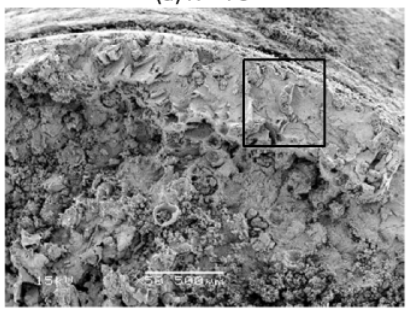

(c) $X=50$
Photograph (a) shows SCC fracture surface at the upper right portion and mechanical fracture surface at the lower left portion. Photograph (b) is the elected area of (a) at $X=200$.

Photograph (c) shows SCC fracture surface at the upper portion and mechanical fracture surface at the lower portion.

Photograph (d) is the elected area of (c) at $X=250$.

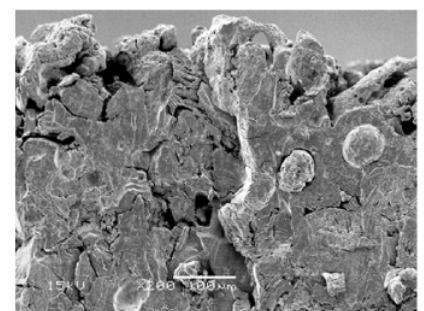

(b) $X=200$

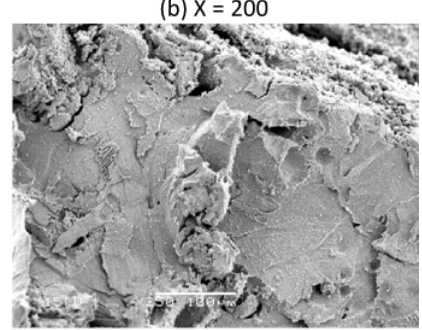

(d) $X=250$

Figure 11. SEM micrographs of $G$ material, G3 specimen, (a), (b) and D material, D1 specimen, (c), (d) showing fracture surface pattern similar to that of failed pump casing shown in figure 9 [7].

In addition to SCC the specimens were simultaneously subjected to uniform corrosion under anodic polarization applied to accelerate the SCC. The effect of uniform corrosion on specimens' final state of stress was examined in accordance with ASTM G49 [5]. This has been done by calculating the clean cross sectional area of each specimen, after SCC testing, and consequently the amount of increase in the applied stress. It can be seen from Table 5 that the average percent in diameter reduction in $\mathrm{D}$ material is relatively higher than that observed in $\mathrm{G}$ material. This can be attributed to the longer periods of testing of the D material. The consequent average stress rise in $\mathrm{D}$ material is comparable with that of $\mathrm{G}$ material. 
However, such increased stresses are still much below the ultimate stresses of both materials. This indicates that the obtained SCC testing results are not biased by area reduction due to uniform corrosion.

The above contrasting behavior in SCC resistance of these two materials can be explained in view of the variation in their yield stress. The $0.2 \%$ offset yield stress of $\mathrm{D}$ material is higher than that of $\mathrm{G}$ material by approximately $40 \mathrm{MPa}$ [6]. According to Miyasaka and Ogure [12] the log of time to failure by SCC is inversely proportional to the applied stress. Even though the ultimate stresses of both materials are approximately equal, the yield stress would practically have a more pronounced effect on SCC resistance. This view point is supported by the fact that SCC takes place at lower stresses than the yield stress as seen in Table 4 and reported by Miyasaka and Ogure [12]. As can be seen from Fig. 5, under a stress value of say $260 \mathrm{MPa}$, which is the yield stress of D material, G material would be subject to a strain value of around $1 \%$ whereas D material would be strained only to a value of $0.33 \%$. This difference in matrix stretching would certainly make G material more prone to SCC as compared to D material. Another possible reason for this difference in performance is the characteristics of graphite nodules in each material.

\begin{tabular}{cccccccc}
\hline Specimen & Load, $\mathbf{N}$ & $\begin{array}{c}\text { Initial Dia., } \\
\mathbf{m m}\end{array}$ & $\begin{array}{c}\text { Initial Stress, } \\
\mathbf{M P a}\end{array}$ & $\begin{array}{c}\text { Final Dia., } \\
\mathbf{m m}\end{array}$ & $\begin{array}{c}\text { Reduction in } \\
\text { Dia., } \%\end{array}$ & $\begin{array}{c}\text { Stress Rise*, } \\
\mathbf{M P a}\end{array}$ & $\begin{array}{c}\text { Final Stress as } \\
\text { \% of Ult. Stress }\end{array}$ \\
\hline $\mathrm{G}_{1}$ & 6836 & 6.22 & 225 & 6.11 & 1.77 & 8.2 & 65.7 \\
\hline $\mathrm{G}_{2}$ & 6452 & 6.16 & 216.5 & 5.86 & 4.87 & 22.7 & 67.4 \\
\hline $\mathrm{G} 3$ & 5723 & 6.18 & 190.8 & 6.00 & 2.91 & 11.6 & 57.0 \\
\hline $\mathrm{G} 4$ & 5856 & 6.26 & 190.3 & 6.18 & 1.28 & 5.0 & 55.0 \\
\hline $\mathrm{D} 1$ & 6757 & 6.19 & 224.5 & 6.09 & 1.62 & 7.4 & 66.9 \\
\hline $\mathrm{D} 2$ & 6190 & 6.19 & 216.5 & 5.80 & 6.30 & 17.8 & 67.5 \\
\hline $\mathrm{D} 3$ & 5940 & 6.30 & 190.6 & 6.15 & 2.38 & 9.4 & 57.6 \\
\hline $\mathrm{D} 4$ & 6379 & 6.28 & 205.9 & 6.09 & 3.03 & 13.0 & 63.1 \\
\hline
\end{tabular}

*Excluding stress rise due to crack effect on section reduction.

Table 5. Effect of specimen reduction in cross sectional area, due to uniform corrosion, on final state of stress [7].

As can be seen from Table 3, the nodules of D material are bigger and fewer in number than $\mathrm{G}$ material. The former has an average diameter that is around $40 \%$ larger than the latter's average diameter. Also number of $\mathrm{D}$ material nodules are half that of $\mathrm{G}$ nodules in the same size of field area. As the SCC is a surface phenomenon taking place at the material surface in contact with the corrosive environment, the size of graphite nodules and their number may be significant. The nodules are non-load bearing and incoherent phase in the iron as clearly shown in SEM micrographs of Fig. 10 which illustrate voids left by nodules and gaps between the matrix and periphery of exposed nodules. Raman [17] has studied the caustic SCC of ductile iron. He found that "where crack encountered graphite nodules, further propagation involved decohesion in the nodule-matrix interface". As such, surface nodules can be considered as micro-cracks or notches. From a fracture mechanics view point the smaller the 
diameter of these natural notches the more is the stress concentration at these points. The nodule count may also have contributed to the different behavior in resistance to SCC. The higher the number of nodules at the exposed surfaces, as in G material, the higher is the possibility of crack initiation and propagation. This is again supported by Raman's findings [17] and makes the time to failure by SCC of G material shorter compared to D material. It was [14] indicated that "assigning of degrees of susceptibility (to SCC) is of questionable merit." To the contrary to this statement the results in this study indicate that ranking of Ni-resists with respect to SCC resistance is viable. This is also in agreement with what Miyasaka and Ogure [12] had reported. Further, the results clearly indicate that the relevant standards [10, 18] for ductile Ni-resists do not provide the required protection against SCC in marine service even after subjecting the cast materials to suitable stress relief heat treatments, again in contrary to what was reported [14] above. For better field performance the standards need modifications based on further studies with regards to mechanical and microstructure properties. This might include carbide characteristics and nodule features so as to arrive at an optimized microstructure leading to best resistance of DNI to SCC in marine environment. Such modifications would necessitate more stringent quality control and assurance procedures in manufacturing facilities. Meanwhile, super duplex stainless steels have found wider use in marine service [19] in recent years and many brine and sea water pumps got their failed DNI casings replaced with such superior materials.

\section{Stainless steels}

Two types of stainless steel are suggested and recommended to substitute Ni resist iron in manufacturing pump casings [3]. These are austenitic stainless steel UNS S31603 and super duplex stainless steel UNS S32750 [20]. In addition to cast stainless steels, original pump manufacturers sometimes use welded construction of wrought stainless steels to build other related components such as column pipes and discharge elbow piece [21]. In fact the desalination plant, in which failures of brine circulating pumps have been reported, has used welded stainless steel S316 material as replacement for failed Ni-resist components [21]. Thus the study of SCC of wrought stainless steels is significant since the long term performance of these materials is still to be seen. In this part, the mechanical, metallurgical, electrochemical and SCC properties of the above mentioned two types of wrought stainless steels are presented through experimental investigation.

\subsection{Experimental work}

\subsubsection{Material preparation and tensile tests}

Two strips of hot rolled plates of UNS S31603 and UNS S32750 having a thickness of 12.7 $\mathrm{mm}$ were cut into samples having dimensions of $250 \times 50 \times 12.7 \mathrm{~mm}$. Chemical analysis, by weight percent of elements in each type of steel is shown in Table 6 [22, 23]. Tensile test samples for each type of stainless steel were prepared as per the ASTM standard A 370-07 
[24].Machining of all samples was carried out using a machining coolant to avoid samples overheat.

\begin{tabular}{llllllllllll}
\hline Material & $\mathbf{C} \%$ & $\mathbf{M n} \%$ & $\mathbf{P} \%$ & $\mathbf{S} \%$ & $\mathrm{Si} \%$ & $\mathrm{Cu} \%$ & $\mathbf{N i} \%$ & $\mathrm{Cr} \%$ & $\mathrm{Mo} \%$ & $\mathbf{N} \%$ & $\mathrm{Co} \%$ \\
\hline UNS S31603 & 0.025 & 1.360 & 0.029 & 0.003 & 0.268 & 0.468 & 10.056 & 16.804 & 2.176 & 0.051 & 0.213 \\
\hline UNS S32750 & 0.017 & 0.893 & 0.031 & 0.0004 & 0.370 & 0.126 & 6.651 & 24.681 & 3.755 & 0.280 & - \\
\hline
\end{tabular}

* The balance each composition is iron.

Table 6. Chemical composition of the two as received types of stainless steel

\subsubsection{Metallographic and hardness tests}

Samples from the as received material of both austenitic UNS S31603 and super duplex UNS S32750 were cut into thin sections using a thin sectioning cutter. A cutting coolant was used during cutting to avoid overheating. Thin sections were then mounted in phenol moulds to be ready for grinding and polishing. Grinding emery papers having grids of 240, 400, 600, 1000, and 2400 were used. Polishing was performed in two stages using $6 \mu \mathrm{m}$, and $1 \mu \mathrm{m}$ diamond pasts. Austenitic stainless steel samples were electrolytically etched using $10 \%$ oxalic acid at $3 \mathrm{~V}$, whereas, super duplex samples were etched using an electrolyte of $20 \% \mathrm{NaOH}$ and $100 \mathrm{ml}$ of distilled water at $3 \mathrm{~V}$ for $20 \mathrm{~s}$. Samples were then examined using an optical microscope and a digital image camera was used to capture microstructures of both steels. For hardness tests, a load of $200 \mathrm{~g}$ was applied on different locations of the microstructure for each tested sample by using Vickers micro hardness testing device. For each type of steel, an average of five different readings has been calculated.

\subsubsection{Electrochemical tests}

\subsubsection{Sample preparation}

Three sets of polarization test samples from the as received austenitic and super duplex stainless steels were cut and machined to dimension of $70 \times 10 \times 5 \mathrm{~mm}$. Each set, consisting of one super duplex and three austenitic stainless steel samples, was connected to insulated electrically conducting wires. The assembly was then molded in an epoxy mixture consisting of a resin and a hardener to ensure complete electrical insulation among samples. Extra care was taken during molding to avoid having air gaps between stainless steel samples and epoxy and hence avoid possible crevice corrosion. Molded samples were manually ground with 100, 200, 400, 600, and 1000 emery papers, degreased using 5\% caustic soda solution and rinsed in fresh water. The electrical wires were passed through water seal PVC tubes and fittings for perfect insulation during immersion in brine solution. Ends of wires were identified and labeled as, austenitic stainless steel working electrode, super duplex stainless steel working electrode, and two additional austenitic stainless steel samples to serve as reference and auxiliary electrodes as shown in Fig. 12 [2]. 


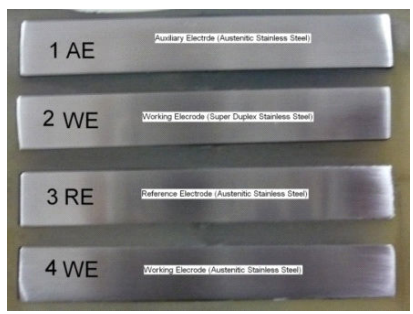

(a)

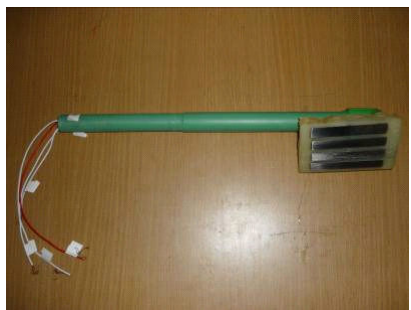

(b)

Figure 12. a) Identification of electrodes in one sample set. (b) Molded samples in epoxy and copper wire passing through water seal PVC tube [2].

\subsubsection{Long term potential measurements}

An ACM potentiostat Gill 8 connected to a computer was used to perform the electrochemical tests, whereas, Sequencer software was used to control and record the test results. Samples were immersed in Pyrex container filled with a temperature controlled brine solution. The brine solution, which is a concentrated sea water of Arabian Gulf having an average chloride concentration of 34,000 ppm, was arranged from the desalination plant where pump casing failures have occurred. Open circuit potentials of the as received austenitic and super duplex stainless steel samples were measured using long term potential measurements. Samples were immersed in brine at $60{ }^{\circ} \mathrm{C}$ and $\mathrm{pH}$ of 8.31 for $1 \mathrm{~h}$ before running the test to take potential measurements for duration of 1 day.

\subsubsection{Cyclic sweep}

Cyclic sweep testing was performed under the above mentioned conditions on stainless steel samples of both types. For austenitic stainless steel, the start potential was set to -250 $\mathrm{mV}$ and the reverse potential to $+750 \mathrm{mV}$ with reference to its open circuit potential. For super duplex stainless steel, the start potential was set to $-250 \mathrm{mV}$ and the reverse potential was set to $+1000 \mathrm{mV}$ with reference to its open circuit potential. The sweep rate was $30 \mathrm{mV} /$ $\min$.

\subsubsection{SCC tests}

\subsubsection{Sample preparation}

Three SCC samples from each type of stainless steel were machined from the as received rolled plates to conform with the NACE type "A" SCC test method [4] and ASTM standard G49 [5]. Machined SCC test samples have gauge diameter and length of $6.24 \mathrm{~mm}$ and $40 \mathrm{~mm}$ respectively. All samples were machined to have the same dimensions. Machining of samples was carried out using a coolant to avoid sample overheating. Samples were manually ground with 100, 200, 400, 600, and 1000 emery papers, degreased using acetone solution, and rinsed in fresh water $[4,5,24]$. 


\subsubsection{SCC testing}

The testing rig and method described earlier in this chapter in section1 (SCC testing rig and method) was used to conduct SCC tests. An ACM potentiostat model Gill 6 was used to apply the required accelerated anodic potential during SCC testing. ACM Sequencer software was used to record the test results. An offset anodic potential of $+400 \mathrm{mV}$ with respect to the rest potential of each of the as received austenitic and super duplex stainless steels was used [25]. The value of this accelerating anodic potential was determined from cyclic sweep based on the pitting potential values observed for the austenitic stainless steel samples. During SCC testing, both types of stainless steel samples were subjected to a constant load of $8403 \mathrm{~N}$ representing $95 \%$ of the yield load of the as received austenitic stainless steel and $43 \%$ of the yield load of the as received super duplex stainless steel. Each SCC test was stopped upon sample fracture or completion of 335 testing hours (14 days), whichever comes first. Samples which were not completely separated into two pieces, by SCC tests, were subsequently forced to mechanical tensile fracture using MTS testing machine. Fracture sections of the mechanically forced fractured samples were examined using SEM. These sections were also compared with fracture sections of fresh samples not subjected to SCC testing. The ultimate tensile loads of both fresh and mechanically forced fractured samples were also compared.

\subsection{Results and discussion}

Table 7 shows the average mechanical testing results of both types of steels. Austenitic steel enjoys better ductility on the expense of its yield and tensile strengths as compared to super duplex steel. The table illustrates considerable differences in the yield and ultimate strengths of the two types. Results of hardness testing have also shown a noticeable difference between both types. Austenitic steel was found to have an average hardness of HV 202.6 as compared to HV 265 for the super duplex steel.

\begin{tabular}{lllll}
\hline & $\begin{array}{l}\text { Yield Strength } \\
\text { N/mm2 }\end{array}$ & $\begin{array}{l}\text { Ultimate Tensile Strength } \\
\text { N/mm2 }\end{array}$ & $\begin{array}{l}\text { Elongation } \\
\%\end{array}$ & Reduction of Area \% \\
\hline Austenitic UNS S31603 & 284 & 597 & 52 & 73 \\
\hline Super duplex UNS S32750 & 608 & 852 & 35 & 68 \\
\hline
\end{tabular}

Table 7. Average mechanical testing data of the as received two types of stainless steel [2].

Fig. 13 shows micrographs for the austenitic steel microstructure at two magnifications. The micrographs illustrate grains of two phases. The austenite which is the majority phase appears in the micrograph as the light phase and ferrite which is the minority phase appears as the dark phase. Elongated ferrite grains indicate the rolling direction. Fig. 14 illustrates micrographs for the as received super duplex stainless steel UNS S32750, showing that ferrite is the majority phase and austenite is the minority phase. 


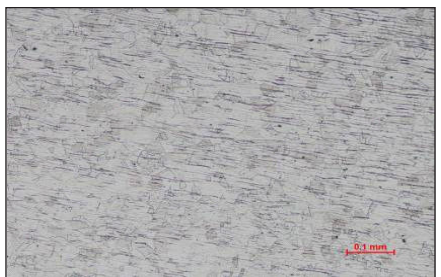

(a)

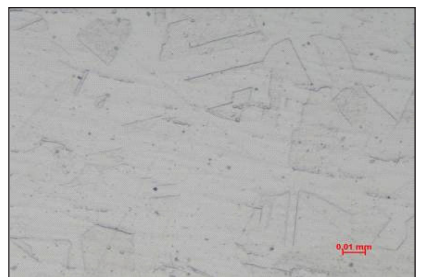

(b)

Figure 13. Microscopic images for the austenitic stainless steel UNS $\$ 31603$ (a) at 100X and (b) at 500X [2].

Fig. 15 shows the open circuit potential graphs for the as received austenitic and super duplex stainless steels. All potentials are measured against austenitic stainless steel as the reference electrode. The average values of the open circuit potentials recorded for the last $4 \mathrm{~h}$ of testing for both types are shown in Table 8 . These values indicate a relatively lower corrosion tendency for super duplex steel. This behavior is schematically illustrated in Fig. 16 using E-Log i diagram.

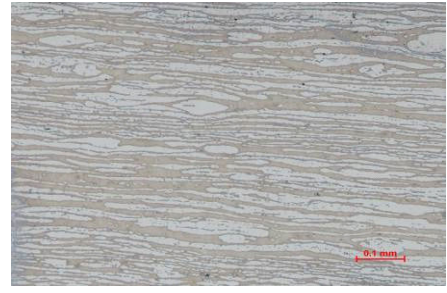

(a)

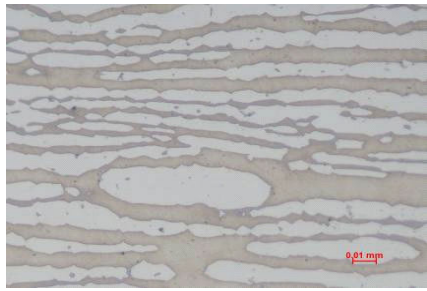

(b)

Figure 14. Microscopic images for the as received super duplex stainless steel UNS S32750, (a) at 100X and (b) at $500 \times[2]$

Fig. 16 shows that when a relatively higher cathodic potential is measured on super duplex stainless steel a correspondent lower current density is expected. On the other hand, higher anodic potential corresponds to higher current densities on the surface of the austenitic stainless steel. The lower corrosion tendency of the super duplex stainless steel is clearly attributed to the relatively higher chromium levels which help form a more stable and a stronger passivity on its surface under these specific test conditions. The enhanced passivity of the super duplex was also confirmed visually by having no signs of pitting and by electrochemical cyclic sweeps.

\begin{tabular}{|l|c|c|}
\hline Material & $\begin{array}{l}\text { Austenitic stainless } \\
\text { steel UNS S 31603 }\end{array}$ & $\begin{array}{l}\text { Super duplex stainless } \\
\text { steel UNS S 32750 }\end{array}$ \\
\hline Average open circuit potential, mV & 7.13 & -24.01 \\
\hline
\end{tabular}

Table 8. Average open circuit potentials for austenitic and super duplex steels during the last four hours of testing[2] 


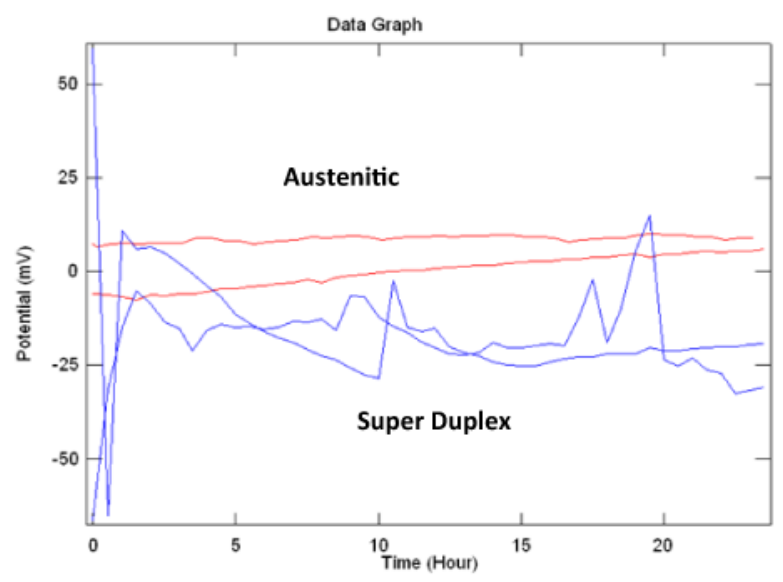

Figure 15. Open circuit potential against time for the as received austenitic and super duplex stainless steels. All potentials are measured against austenitic stainless steel reference electrode [2].

Cyclic sweep test plots are shown in Fig. 17 for austenitic and super duplex stainless steels. Results of these tests indicate that localized break down in the passivity in the form of a clear pitting takes place for austenitic steel at any potential between 275 and $398 \mathrm{mV}$ measured versus austenitic reference electrode. The pitting behavior on the surface of the austenitic stainless steel was also confirmed by visual inspection of tested samples.

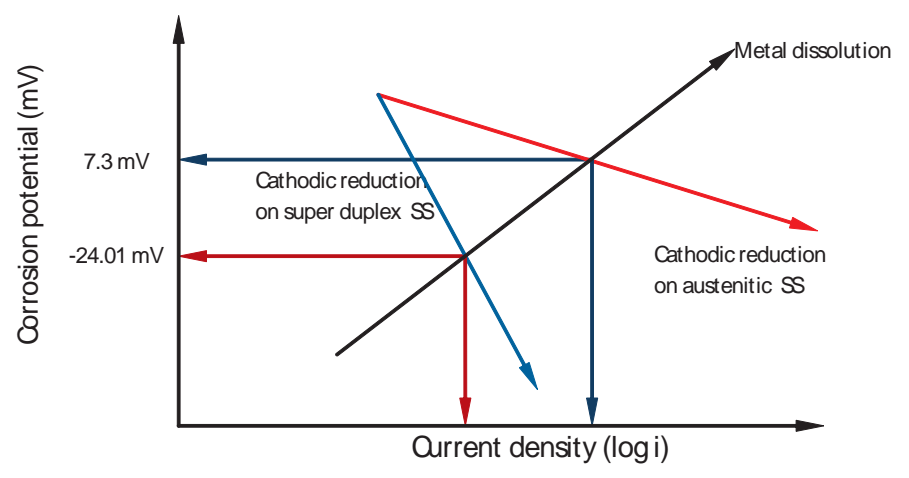

Figure 16. Schematic for (E- log i) diagram illustrating higher corrosion tendency for austenitic stainless steel versus relatively lower corrosion tendency on super duplex stainless steel [2].

Fig. 18 depicts photographs showing pitting of the austenitic sample. The super duplex specimens showed no signs of pitting after cyclic sweep testing. Similar results have been reported in literature $[26,27]$. 


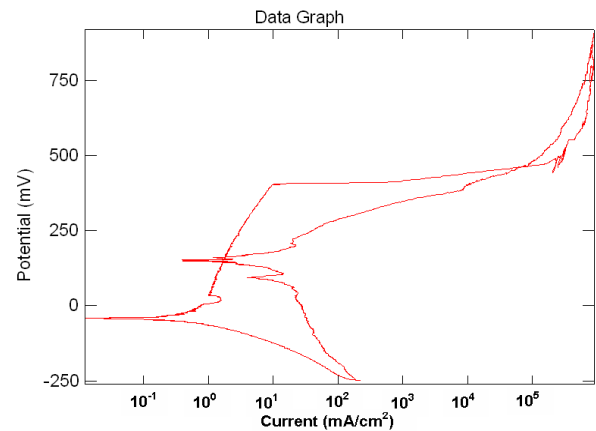

(a)

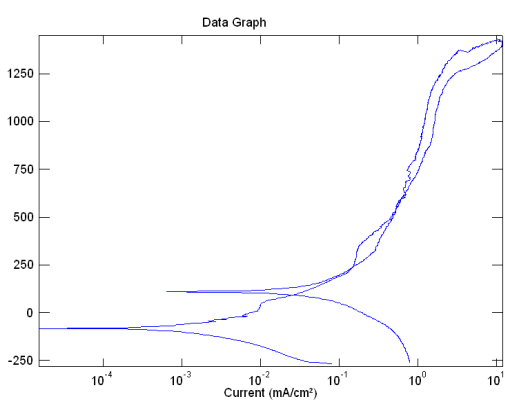

(b)

Figure 17. Cyclic sweep potential plots against current density for the as received (a) austenitic and (b) super duplex stainless steels. All measured potentials are measured versus austenitic stainless steel reference electrode[2].

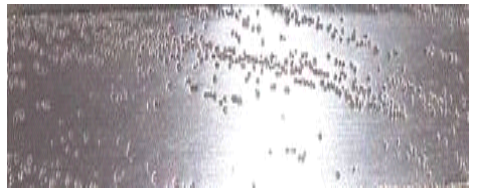

(a)

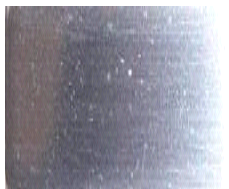

(b)

Figure 18. Pitting on austenitic sample (a) as compared by no pitting on super duplex sample (b) after one run of cyclic sweep testing [2].

Table 9 shows the recorded time to failure of both types of stainless steel due to SCC testing. The table shows that the first and third samples of austenitic stainless steel failed, after $160.29 \mathrm{~h}$ and $119.56 \mathrm{~h}$ respectively. Both samples were failed without complete separation into two pieces. The second sample failed after considerable less time of $76.38 \mathrm{~h}$ with complete sample separation.

\begin{tabular}{lcc}
\hline Material & $\begin{array}{c}\text { Time to failure, hours } \\
\text { Austenitic steel UNS S 31603 }\end{array}$ & $\begin{array}{c}\text { Time to failure, hours } \\
\text { Super duplex steel UNS S 32750 }\end{array}$ \\
\hline Sample 1 & $160.29^{1}$ & No failure $^{3}$ \\
\hline Sample 2 & $76.38^{2}$ & No failure $^{3}$ \\
\hline Sample 3 & $119.56^{1}$ & No failure $^{3}$ \\
\hline
\end{tabular}

${ }^{1}$ Failure without complete sample separated into two pieces. ${ }^{2}$ Failure with complete sample separation into two pieces. ${ }^{3}$ SCC test stopped after 335 hours.

Table 9. Time to failure for austenitic and super duplex stainless steels due to SCC testing [2]. 
The maximum recorded subsequent tensile load required to bring the first sample to complete separation was found to be $2911.81 \mathrm{~N}$ versus $18,640 \mathrm{~N}$; the average maximum tensile load for fresh samples (15.62\% remaining strength). The remaining strength of the third sample was calculated and found to be $43.45 \%$. In all three samples of austenitic stainless steel, it was noticed that, during SCC testing, pits were developed on their surfaces. This was confirmed by further visual examinations by the end of each test. These examinations revealed also many small cracks and some of them were joined together to form major ones.

Table 9 illustrates also that all super duplex three samples didn't fail and SCC tests were stopped after $335 \mathrm{~h}$ of testing. Visual observations showed, however, that under the reported test conditions and after $335 \mathrm{~h}$ of SCC testing, two super duplex samples had completely clean surfaces while the third sample had a single shallow pit on its surface. Subsequent forced tensile fracture of all samples, using the MTS machine revealed no strength losses due to SCC testing.

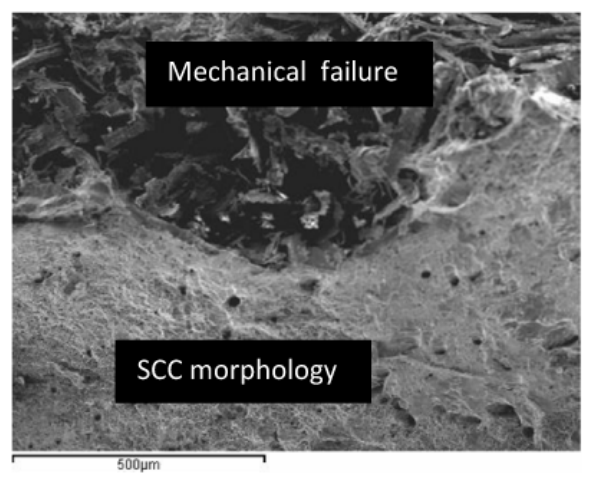

a

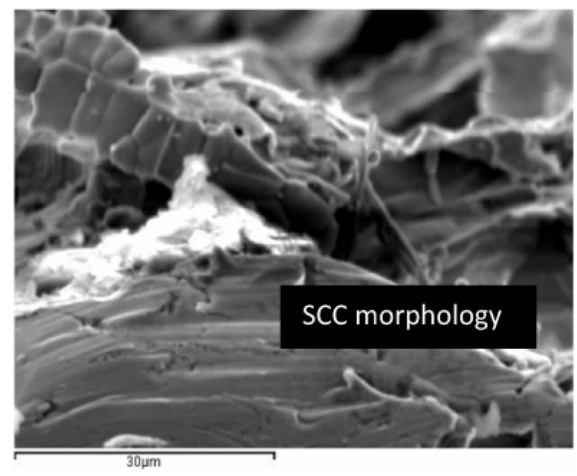

b

Figure 19. Fracture section of failed austenitic stainless steel sample due to SCC at X 200 (a) and X 3500(b) [2].

Fig. 19 shows fracture section micrographs of failed austenitic stainless steel sample due to SCC at two magnifications. In Fig. 19a, two different morphologies can be identified for the fracture section; one associated to the progress of cracking due to stress corrosion and the other one corresponds to fast mechanical fracture as the section is reduced due to SCC. In Fig. 19b, step like topography together with SCC facets which are analogous to cleavage facets are shown [28]. Fig. 20 shows fracture sections of super duplex stainless steel samples before and after SCC testing. Both micrographs illustrate typical ductile fracture characteristics where dimpled fracture can be identified. Comparing the micrographs of Fig. 20 reveals that their fracture surfaces are identical and that there is no sign for SCC failure. 


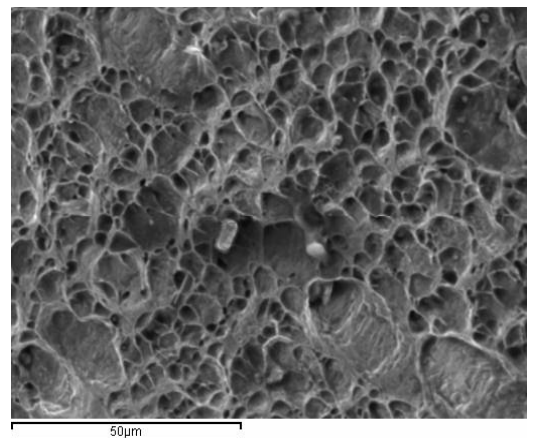

(a)

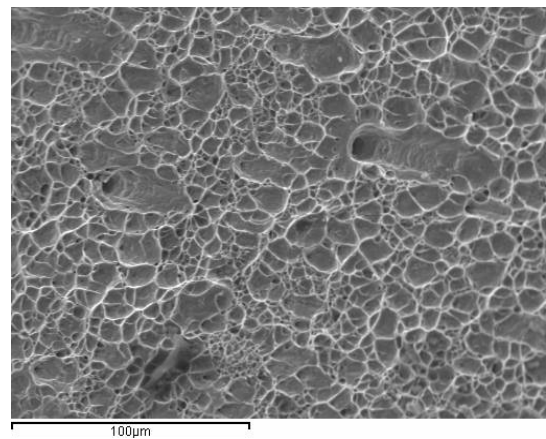

(b)

Figure 20. Fracture sections of super duplex stainless steel samples before SCC testing, X 2000 (a) and after 335 hours of SCC testing, X 1000 (b). Both samples were forced to mechanical failure using the MTS testing machine [2].

\section{Corrosion inhibition of austenitic stainless steel}

The above results demonstrate the superiority of the SCC resistance of the super duplex stainless steel UNS S32750 over the austenitic stainless steel UNS S31603 in hot brine environment. However, due to the remarkable difference in price between these two types of stainless steels, and in case of using ASS in some pump casing metallurgies, an attempt is made to improve the immunity of the cheaper austenitic stainless steel through using chemical treatment via one proven performance corrosion inhibitor [29]. The following represents a study on the effect of using a passivating type commercially available Molybdate corrosion inhibitor on the corrosion resistance and SCC of austenitic stainless steel UNS S31603 in hot brine environment. Sodium Molybdate was selected to inhibit this type of stainless steel as it is effective at relatively low concentrations, environmentally safe, non toxic and known to passivate pits and crevices from corrosion [30]. Several works have been reported indicating the use of Molybdate solutions to inhibit different types of austenitic stainless steels in different environments [31, 32].

\subsection{Experimental work}

\subsubsection{Sample preparation}

For each of the following electrochemical tests, given in the next subsections, two sets of polarization test samples from the as received austenitic stainless steel UNS S31603, given in table 6, were prepared. One set was used as a control set for testing the electrochemical properties of the stainless steel in regular hot brine without inhibitor. The other set was used to get the same properties when the stainless steel samples were subjected to the same brine environment in the presence of a commercial type passivating Molybdate corrosion inhibitor. The treat rate of the corrosion inhibitor was $350 \mathrm{ppm}$ in all treated brine solutions. 
Each set of the prepared test samples consisted of four austenitic stainless steel samples each having dimensions of 70X10X5 mm and connected to insulated copper wires. Each set was prepared as described earlier in section 4.1.3 and Fig. 12. Ends of copper wires were identified and labeled as, two austenitic stainless steel working electrodes, and two austenitic stainless steel samples as reference and auxiliary electrodes. Molded samples were manually ground with 100, 200, 400, 600, and 1000 emery papers, degreased using 5\% caustic soda solution and rinsed in fresh water.

\subsubsection{Cyclic sweep tests}

An ACM potentiostat Gill 6 connected to a computer was used to perform cyclic sweep tests, whereas, Sequencer software was used to control and record the test results. Samples were immersed in Pyrex container filled with a temperature controlled regular (uninhibited) or inhibited brine solution.The regular brine solution, which is a concentrated sea water of Arabian Gulf having an average chloride concentration of 34,000 ppm, was arranged from the desalination plant where relevant pump failures have occurred. Samples of one set were immersed in regular brine solution at $55^{\circ} \mathrm{C}$ and $\mathrm{pH}$ of 8.31 for 24 hours before running the tests. Similar tests were performed on samples of the second set which were immersed in inhibited brine solution under the same testing conditions. The start potential was set to -250 $\mathrm{mV}$ and the reverse potential to $+750 \mathrm{mV}$ with reference to the corresponding sample open circuit potential. The sweep rate was $30 \mathrm{mV} / \mathrm{min}$ [29].

\subsubsection{SCC tests}

Six SCC samples were machined from the as received rolled plates to conform with the NACE type "A" SCC test method [4] and ASTM standard G49 [5]. A machined SCC test sample has a gauge diameter and length of $6.24 \mathrm{~mm}$ and $40 \mathrm{~mm}$ respectively and has already been shown in Fig. 3.c. All samples were machined to have the same dimensions. Machining of samples was carried out using a coolant to avoid sample overheating. Samples were manually ground with 100, 200, 400, 600, and 1000 emery papers, degreased using acetone solution, and rinsed in fresh water [4, 5, 24]. SCC tests were performed using the test rig described earlier in this chapter in section 2 . An offset anodic potential of $+400 \mathrm{mV}$ with respect to the rest potential of each as received austenitic stainless steel sample was used. The value of this accelerating anodic potential was determined from cyclic sweep tests based on the pitting potential values observed for austenitic stainless steel without inhabitation. Austenitic stainless steel samples were subjected to a constant load representing $95 \%$ of the yield load of the as received austenitic stainless steel material. Each SCC test was stopped upon sample fracture or completion of 335 testing hours (14 days), whichever occurred first [29].

\subsection{Results and discussion}

Potentiodynamic scans (cyclic sweeps) are used to stress the metal in short laboratory periods and illustrate the performance. Cyclic sweep test plots from these experiments are shown in Fig. 21 for austenitic stainless steels without inhibition and with inhibition respectively. Results of these tests indicated that after 24 hours of immersion the open circuit po- 
tential of the austenitic stainless steel has been slightly shifted $(60-70 \mathrm{mV})$ in the noble direction due to the change in the metal passivity resulting from the chemical treatment. The plots show also that, without inhibition, pitting takes place for austenitic steel at an average potential of $337 \mathrm{mV}$ measured versus austenitic reference electrode, while an average pitting potential of $318 \mathrm{mV}$ with inhibition was observed. Pitting was observed on all austenitic samples following cyclic sweep tests. Pits are believed and known to be the initiation sites for any possible SCC behavior that the material could undergo under specific combination of environment and stress conditions.

SCC test results and consequent times to failure are shown in table 10 for austenitic stainless steel samples tested in uninhibited and in inhibited brine solutions. Table 10 shows that the average time to failure for samples tested in uninhibited solution is approximately 119 hours. During the tests, many pits were noticed on the surface of this austenitic stainless steel samples. Further visual examinations have carried out after sample failure. This examination showed many small cracks on the surface and some of them were combined together to form bigger ones. Table 10 shows also that the average time to failure for samples tested in Molybdate inhibited solution is approximately 54 hours.

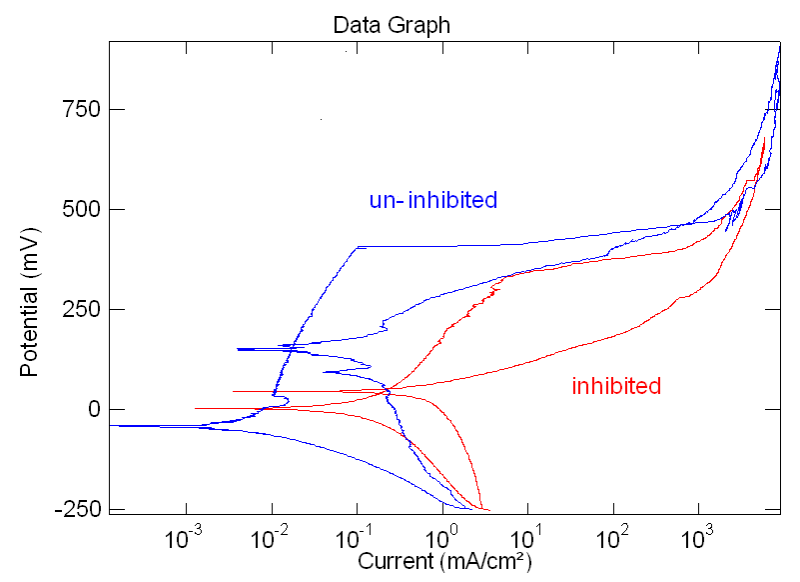

Figure 21. Cyclic sweep test plots for austenitic stainless steel in hot brine without inhibition and with inhibition. All measured potentials are measured versus austenitic stainless steel reference electrode [29].

\begin{tabular}{l|llllll}
\hline \multirow{2}{*}{ Material } & \multicolumn{2}{l|l}{$\begin{array}{l}\text { Austenitic stainless steel UNS S } \\
\mathbf{3 1 6 0 3} \text { without inhibition }\end{array}$} & \multicolumn{2}{l}{$\begin{array}{l}\text { Austenitic stainless steel UNS S 31603 } \\
\text { after inhibition }\end{array}$} \\
\cline { 2 - 7 } & Sample 1 & Sample 2 & Sample 3 & Sample 1 & Sample 2 & Sample 3 \\
\hline Time to failure (Hours) & 160.29 & 76.38 & 119.56 & 32.56 & 58.53 & 71.59 \\
\hline
\end{tabular}

Table 10. Times to failure for austenitic stainless steel samples tested under SCC conditions in uninhibited and in Molybdate inhibited brine solutions [29]. 
Figure 22 below is an attempt to use Evans's diagrams to possibly explain the behaviors for the metals under the inhibited and the uninhibited environments.

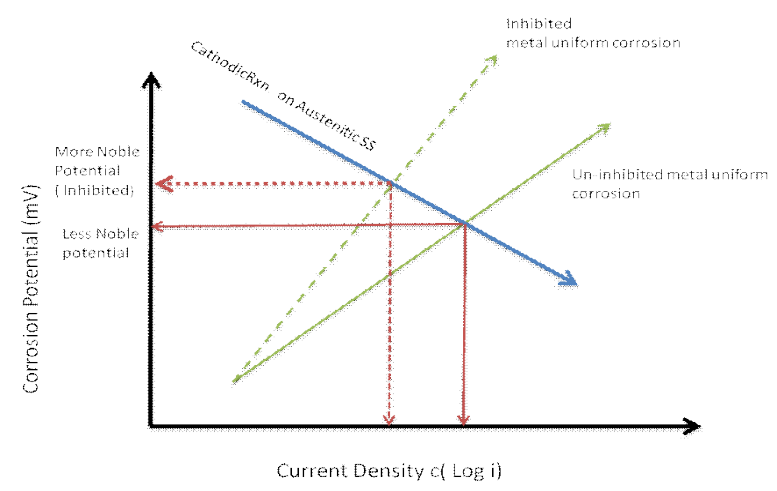

Figure 22. Evans Diagram illustrating results from cyclic sweeps due to environment chemical inhibition [29].

As per the diagram, inhibition of the environment using a passivating type, Molybdate inhibitor caused a relative noble shift in the ASS free corrosion potential. This change in the potential is possibly as a result of inhibitor molecules causing passivation on the metal surface. The shift to the more noble potential could be leading to a reduction in the uniform corrosion rate of the metal. However, this apparent reduction in uniform corrosion rate is not persistent and when the metal is stressed under real life operating conditions (simulated in cyclic sweeps in the lab tests) the intrinsic metal passivity might be adversely affected. The measured shift in potential and this apparent change in passivity are not necessarily enhancing metal resistance for localized corrosion (pitting). In fact this is adversely affecting the metal passivity as cyclic sweeps are showing a relative decrease to the pitting potential when compared to the uninhibited pitting potential. These results are also confirmed by the visual pitting observed on the metal after the test exposure and by the reduction in time to failure in the SCC tests.

\section{Conclusions}

1. Two common grades of ductile Ni-resist cast irons are widely used for sea water applications which include brine circulation pump casings. The first one is made as per ASTM A439 D2 (denoted in table 1 by D-material), whereas, the second one is made as per BS 3468 S2W (denoted by G-material), which has better weldability. The service lives of pump casings made of these two materials had been reported to be considerably different. The microstructure of each type of cast irons is different in terms of nodularity of graphite nodules, nodule count per square millimeter and uniformity of distribution of chromium carbides. This difference in microstructure is reflected in var- 
iations, in hardness and tensile strength of both alloys. The D-type Ni-resist ductile iron has a relatively higher bulk hardness and higher tensile properties. However, electrochemical corrosion tests, in brine solution at room temperature, have shown similar corrosion behavior, in terms of corrosion rates, potential and polarization.

2. SCC tests in brine environment have indicated that $\mathrm{D}$ material has higher resistance to SCC than that of G material. SEM micrographs indicated that SCC failed specimens had distinctive fracture surface pattern identical to that of examined failed pump casings. This emphasizes that the cause of pump failure is SCC. The difference in behavior in resistance to SCC of the two materials is attributed to mechanical and microstructural properties. Further studies are recommended on the effects of carbides and nodules features, in DNI, on the resistance to SCC. This will allow optimization of SCC resistance of these materials.

3. Two types of stainless steel have been recommended as better substitutes to DNI in building brine circulation pump casings. These are austenitic UNS S31603 and superduplex UNS S32750. The corrosion resistance of the super duplex steel is relatively higher than that of the austenitic steel. This was demonstrated by a lower corrosion potential or enhanced passivity. Under the reported test conditions austenitic stainless steel showed clear breakdown in its passivity indicated by electrochemical cyclic sweeps, pitting potentials and visual observations.

4. Austenitic stainless steel showed susceptibility to SCC when loaded to $95 \%$ of its yield strength, polarized to a potential close to its pitting potential and exposed to fresh circulating brine at $55-60{ }^{\circ} \mathrm{C}$. Pitting of austenitic stainless steel under these conditions is believed to stimulate crack initiation and hence the start of SCC. The lower strength and pitting resistance of austenitic stainless steel are believed to be the main reasons for its lower resistance to SCC compared to the super duplex steel.

5. Super duplex stainless steel showed immunity to SCC under the above mentioned testing conditions. Pitting is the mode of attack of most passive materials and can also be found on super duplex stainless steels possibly at higher corrosion accelerating potentials.

6. Fracture section of failed SCC austenitic stainless steel is characterized by having two zones; the first has step like features and facets analogous to cleavage facets, and the second corresponds to a dimpled fracture section, characteristic of ductile mechanical fracture.

7. Compared to austenitic stainless steel, super duplex stainless steel stands better chances of longer life as an engineering material used for building brine and sea water pump components.

8. Corrosion resistant alloys are expensive due to the presence of alloying elements that are essential to the corrosion resistance of these metals under challenging corrosive environments. Corrosion resistant alloys rely on their intrinsic passivity acquired from alloying additions. 
9. Trying to enhance the passivity using Molybdate as passivating type inhibitors did not prove to help enhance corrosion resistance of ASS in hot brine environment. Under the given test conditions and using 350 ppm of Molybdate corrosion inhibitor, ASS showed localized corrosion in the form of pitting and failed in relatively shorter times in SCC tests. Thus using Molybdate as corrosion inhibitor does not eliminate the need for higher and more expensive alloy metallurgy to further improve corrosion resistance and SCC. However, still the idea of trying other inhibitor chemistries such as nitrites, carboxylates, orthophosphates, phosphates and other synergistic- types for inhibiting ASS in hot brine environment worth trying.

\section{Author details}

Osama Abuzeid ${ }^{1}$, Mohamed Abou Zour ${ }^{2}$, Ahmed Aljoboury ${ }^{3}$ and Yahya Alzafin ${ }^{4}$

*Address all correspondence to: o.abuzeid@uaeu.ac.ae

1 Mechanical Engineering Department, UAE University, Al- Ain, The United Arab Emirates

2 General Electric Water \& Process Technologies ME, Dubai, The United Arab Emirates

3 Industrial Support Services, Abu Dhabi, The United Arab Emirates

4 Dubai Electricity \& Water Authority, Dubai, The United Arab Emirates

\section{References}

[1] http://en.wikipedia.org/wiki/Multi-stage_flash_distillation\#cite_note-0. Retrieved 18-7-2012.

[2] A. I. Aljoboury, A.-H. I. Mourad, A. Alawar, M. Abou Zour and O.A. Abuzeid, "Stress corrosion cracking of stainless steels recommended for building brine recirculation pumps", Journal of Engineering Failure Analysis, Elsevier, 17,pp: 1337-1344, 2010 .

[3] Private communication with pump manufacturer; 2007.

[4] ANSI/ NACE Standard TM0177, 1996.

[5] ASTM Standard G49-85, 2000.

[6] Y. A. Alzafin, A.-H. I. Mourad, M. Abou Zour, O. A. Abuzeid, "A Study on the failure of pump casings made of ductile Ni-resist irons used in desalination plants", Journal of Engineering Failure Analysis, Elsevier, Volume 14, Issue 7, pp 1294- 1300, 2007. 
[7] Y. A. Alzafin, A.-H .I. Mourad, M. Abou Zour, O. A. Abuzeid,"Stress Corrosion Cracking of Ni-resist Ductile Iron Used In Manufacturing Brine Circulating Pumps of Desalination Plants", Journal of Engineering Failure Analysis, Elsevier, 16, pp: 733-739, 2009.

[8] Standard test methods for tension testing of metallic materials [Metric], E 8M-00b Metric, 2000.

[9] Standard practice for preparing, cleaning and evaluating corrosion test specimens, ASTM G1-03, 2003.

[10] Standard specifications for austenitic ductile iron castings, ASTM A 1999; 439-83.

[11] Standard test methods and definitions for mechanical testing of steel products. ASTM A370-02; 2002.

[12] Miyasaka M, Ogure N. Corrosion 1987;:43(10):582-8.

[13] Materials for saline water, desalination and oilfields brine pumps. A nickel development institute technical series No. 11004, 2nd ed., 1995.

[14] Properties and applications of Ni-resist and ductile Ni-resist alloys. A nickel development institute reference book series No. 11 018, Nickel Development Institute; 1998.

[15] Smart NG, Hitchman ML, Ansell RO, Fortune JD. A study of the electrochemical properties of Ni-resist in 3\% sodium chloride solution. Corros Sci 1994;36(9):1473-89.

[16] Case histories in failure analysis. ASM; 1979.

[17] Singh Raman RK, Muddle BC. Eng Failure Anal 2004;11:199-206.

[18] British Standard Specification for Austenitic Cast Irons. BS 3468; 1986.

[19] Private communication from Bryan Johnson. CSS Technical Support, Sulzer Pumps, UK; 2007.

[20] ASTM A 240; 2006.

[21] Private communication with the Vice President - Plant 1 (D, E and G), Generation Division, Dubai Electricity and Water Authority, The United Arab Emirates; 2010.

[22] Mill Test Reports. Provided by Industeel, the material manufacturer; 2007.

[23] Metallurgical Test Report. Provided by North American Stainless, the material manufacturer; 2007.

[24] ASTM A370-07; 2007.

[25] ASTM G5-94 [reapproved 2004].

[26] Kwok CT, Fong SL, Cheng FT, Man HC. J Mater Process Technol 2006;176:168-78.

[27] Breslin CB, Chen C, Mansfeld F. Corros Sci 1997;39(6):1061-73. 
[28] Fractography. ASM handbook; 1987.

[29] O. A. Abuzeid, A.I. Aljoboury, M. Abou Zour, "Effect of Corrosion Inhibition on the Stress Corrosion Cracking of UNS S31603 Austenitic Stainless Steel", Advanced Materials Research Vols. 476-478 (2012) pp 256-262.

[30] E. Flick, Corrosion Inhibitors :An Industrial Guide, second edition, New Jersey: Noyes Publications. (1993).

[31] R. Nishimura and Sundjono, Effect of Chromate and Molybdate on stress corrosion cracking of type 304 austenitic stainless steel in Hydrochloric acid solution, Corrosion. 56 (2000), 361-370.

[32] A. Devasenapathi and V. S. Raja, Effect of externally added Molybdate on repassivation and SCC behavior of AISI 304 SS in 1M HCl, Corrosion. 52 (1996), 243-249. 
